\title{
Nonlinear Progressive Collapse Analysis Including Distributed Plasticity
}

\author{
Osama Ahmed Mohamed, Zubair Syed Imam and Rania Khattab \\ College of Engineering, Abu Dhabi University, United Arab Emirates
}

\begin{abstract}
This paper demonstrates the effect of incorporating distributed plasticity in nonlinear analytical models used to assess the potential for progressive collapse of steel framed regular building structures. Emphasis on this paper is on the deformation response under the notionally removed column, in a typical Alternate Path (AP) method. The AP method employed in this paper is based on the provisions of the Unified Facilities Criteria - Design of Buildings to Resist Progressive Collapse, developed and updated by the U.S. Department of Defense [1]. The AP method is often used for to assess the potential for progressive collapse of building structures that fall under Occupancy Category III or IV. A case study steel building is used to examine the effect of incorporating distributed plasticity, where moment frames were used on perimeter as well as the interior of the three dimensional structural system. It is concluded that the use of moment resisting frames within the structural system will enhance resistance to progressive collapse through ductile deformation response and that it is conserative to ignore the effects of distributed plasticity in determining peak displacement response under the notionally removed column.
\end{abstract}

\section{Introduction}

Progressive collapse of building structures is not covered extensively in international building codes and design standards. The U.S. Department of Defense (DoD) publishes UFC 4-023-03, a guide for progressive collapse resistant design of buildings structures [1].

A building structure is assessed for progressive collapse potential, after it is designed in accordance with the applicable building code. The structural system is assessed in terms of its capacity to transfer loads in ductile manner, after the loss of primary load-carrying members. Framed structures are assessed by quantifying the consequences of the notional removed of critical corner, interior, and exterior columns. Loss of corner columns is particularly critical because its leads to long unsupported spans [2].

The current UFC guide [1] embraces the design philosophy that that progressive collapse resistant steel structures are ductile systems, similar in some ways to earthquake resistant structural systems, particularly when certain types of moment resisting connections are used [3]. Several researchers suggested that lessons learned from decades of studying structural performance during earthquakes that aim at producing ductile structural systems could guide engineers in producing progressive collapse resistant systems [4]. UFC defines the required strength for each structural component as force-controlled or deformation-controlled, based on the forcedeformation relationship for the required strength.

This paper outlines the application of the AP method to assess the capacity of steel structural systems to transmit gravity load, following the loss of a primary load carrying member in a framed steel structural system using nonlinear static analysis procedures. Dynamic effects associated with the sudden removal of column are incorporated using load increase factors. Linear analysis procedures are the dominant methods in professional design offices for a large class of structures, with the exception of geometric nonlinearities in steel structures that must be rigorously investigated. The application of the AP method using Linear Static Analysis (LSA) procedures is permitted for structures that do not contain significant irregularities or if the demand-to-capacity ratio (DCR) is less than 2.0. The computationally more expensive Nonlinear Static Analysis (NSA) is permitted without limitations on DCR or structural irregularities. The use of LSA and NSA with the AP method is permitted by UFC [1] and is justified in two ways: 1) The computational cost of LSA and NSA is lower than dynamic analysis, 2) progressive collapse is hazard independent and involves significant uncertainties that justify using approximate methods such as LSA and NSA. This paper is based upon Mohamed et al. [5], which examines the use of LSA procedures for AP investigations. The current paper employs NSA to assess the potential for progressive collapse of steel framed structures and addressed the effect of ignoring distributed plasticity on deformation response.

\section{Nonlinear static analysis procedure and the alternate path method}

The alternate path method is one of the most commonly used procedures to assess the ability of the structure to 
transmit gravity loads safely to competent foundation. The requirement to use the AP method depends on the building Occupancy Category (OC). AP method is typically required for OC III and OC IV, and in some cases for OC II. OCs are defined in UFC 3-301-01 Structural Engineering [6]. Occupancy categories defined in UFC 3-301-01are similar to the Risk Categories currently used in ASCE 7 - 10 [7].

\subsection{Gravity load for assessment of progressive collapse potential}

Progressive collapse is a gravity driven extreme event. In order to assess the vulnerability of a building structure to progressive collapse, alternate path analysis is conducted after the notional removal of selected columns [1]. Prescribed gravity loads are applied and force-controlled and deformation-controlled actions are determined. These actions are compared to certain acceptance criteria, which may be incorporated in the analysis software.

Deformation-controlled and force-controlled actions on the structural system obtained using NSA procedure are calculated by applying amplified gravity loads, given by Eq. 1 to the floor panels adjacent to the notionally removed column at all floor levels $[1,5]$.

$$
G_{N}=\Omega_{N}[1.2 D+0.5 L]
$$

where,

$G_{N}$ : Increased gravity loads for deformation controlled actions calculated using NSA method.

$D$ : Service dead loads including façade $(\mathrm{kN} / \mathrm{m} 2)$

$L$ : Service live load including applicable reductions, per ASCE 7-10 $\left(\mathrm{kN} / \mathrm{m}^{2}\right)$

$\Omega_{N}$ : Dynamic increase factor for calculating deformation-controlled and force-controlled actions using NSA method.

Eq. 2 represents the gravity loads on floor panels that are not adjacent to notionally removed columns, and used to determine either deformation-controlled or forcecontrolled actions, as appropriate. The gravity loads in Eq. 1 and Eq. 2 are applied simultaneously at all floor levels.

$$
G=1.2 D+0.5 L
$$

The gravity load for LSA procedures is similar to NSA, except that a Load Increase Factor (LIF) is used instead of the dynamic increase factor indicated in Eq. 1. Progressive collapse assessment using the alternate path method and LSA procedures as well as the process for determination of LIF are discussed elsewhere $[1,8]$. The discussion in this paper is limited to deformationcontrolled actions.

\section{Dynamic increase factor}

In this study, the AP method was applied using nonlinear static analyses, where the dynamic effects of load removal are approximated through the use of dynamic increase factors (DIF) as shown in Eq. 1.
For steel framed structures, the dynamic increase factor (DIF), $\Omega_{N}$ to be used in Eq. 1 is defined as $\Omega_{N}=1.08+0.76 /\left(\theta_{p r a} / \theta_{y}+0.83\right)$, in which $\theta_{\text {pra }}$ is the plastic rotation angle, and $\theta_{y}$ is the yield rotation [9].

\section{Acceptance criteria}

For deformation-controlled actions calculated using NSA, the acceptance is not based on component strength, but rather on deformation limit controlled by acceptance criteria [1]. The post-yield behaviour is simulated in this paper by inserting concentrated plastic hinges on steel frame objects. The hinge model used in this study to conduct NSA is shown in Fig. 1.

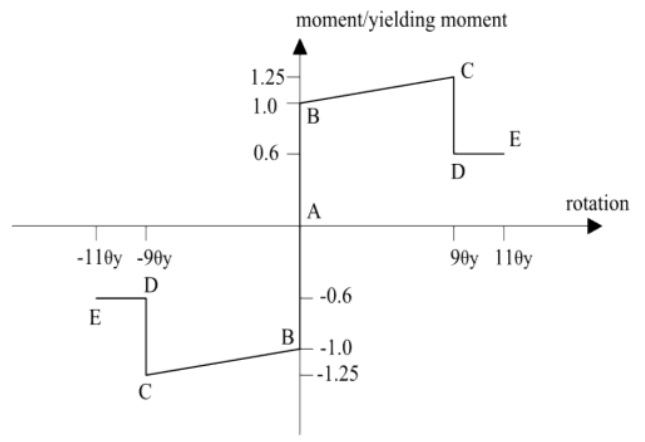

Figure 1. Nonlinear hinge model for nonlinear static analysis.

The plastic hinge parameters and acceptance criteria for selected shapes are shown in the table below [9]. The w-shapes shown below represent some of the design sections for the case study discussed in a subsequent section of this paper.

Progressive collapse is an extreme event; therefore, the acceptance criteria used for NSA and applied to deformations is based on collapse prevention, as recommended by [1].

NSA conducted in this paper for progressive collapse assessment, assumes plastic hinges described in Fig. 1 is assigned to frame members. The plastic hinge length is as per FEMA 356 [9].

\section{Case study}

In order to evaluate the effect considering or ignoring distributed plasticity when conducting nonlinear static analysis during AP investigation, the case study developed by Mohamed and Tarmoom [5] is adopted. The building structure described by Fig. 2 and Fig. 3 was analysed and designed. The floor system is a reinforced concrete slab on a steel deck. All secondary beams were designed as composite beams while moment resisting frames were designed without composite action. Ordinary moment resisting frames exist along the perimeter of the building and along grid lines $\mathrm{A}$ to $\mathrm{H}$. 
The case study conservatively ignores the contribution of the deck to progressive collapse resistance. Consideration of composite action in assessment of progress collapse was discussed in the literature [10]. The member shown in Fig. 2 and Fig. 3 were sized for reducible live load including light weight partitions of 3.6 $\mathrm{kN} / \mathrm{m}^{2}$. The weight of the concrete-filled steel deck was $2.79 \mathrm{kN} / \mathrm{m}^{2}$. Superimposed dead load was assumed to be $4 \mathrm{kN} / \mathrm{m}^{2}$, along with cladding load of $3.2 \mathrm{kN} / \mathrm{m}$. The relatively high gravity load ensures progressive collapse is indeed gravity driven. Design wind speed was 161 $\mathrm{km} / \mathrm{hr}$.

The steel framed structure was designated as OC III and was analysed and designed according to AISC LRFD specifications [11], using the Direct Analysis Method. The longest span of 10 meter was chosen so as to reflect the effect of long spans in exacerbating progressive collapse.

\begin{tabular}{|c|c|c|c|c|c|c|}
\hline \multirow{3}{*}{ Beam } & \multicolumn{2}{|c|}{$\begin{array}{c}\text { Plastic Rotation } \\
\text { Angle }\end{array}$} & $\begin{array}{c}\text { Residual } \\
\text { Strength } \\
\text { Ratio }\end{array}$ & \multicolumn{3}{|c|}{ Acceptance Criteria } \\
\hline & & & & \multicolumn{3}{|c|}{ Plastic Rotation Angle, Radians } \\
\hline & a & b & $\mathrm{c}$ & $\begin{array}{l}\text { Immediate } \\
\text { Occupancy }\end{array}$ & $\begin{array}{l}\text { Life } \\
\text { Safety }\end{array}$ & $\begin{array}{l}\text { Collapse } \\
\text { Prevention }\end{array}$ \\
\hline $\begin{array}{l}\text { W610x113 } \\
(\mathrm{W} 24 \times 76)\end{array}$ & $9 \theta \mathrm{y}$ & $11 \theta y$ & 0.6 & $1 \theta \mathrm{y}$ & $6 \theta y$ & $8 \theta \mathrm{y}$ \\
\hline $\begin{array}{l}\text { W610x372 } \\
(W 24 \times 250)\end{array}$ & $9 \theta y$ & $11 \theta y$ & 0.6 & $1 \theta y$ & $6 \theta y$ & $8 \theta y$ \\
\hline $\begin{array}{l}\text { W530x138 } \\
\text { (W21x93) }\end{array}$ & $9 \theta \mathrm{y}$ & $11 \theta y$ & 0.6 & $1 \theta \mathrm{y}$ & $6 \theta \mathrm{y}$ & $8 \theta \mathrm{y}$ \\
\hline
\end{tabular}

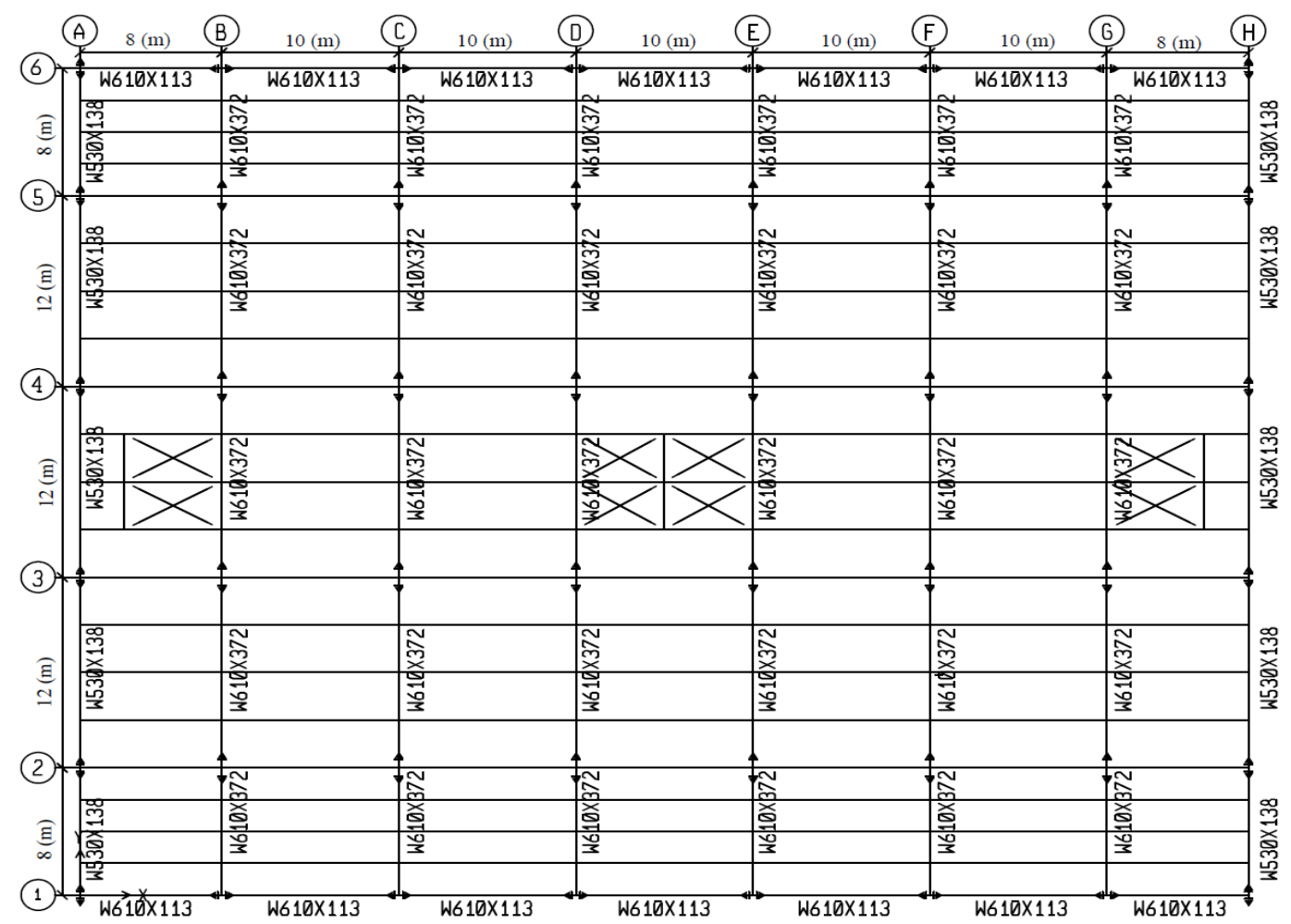

Figure 2. Typical plan view of case-study 15 -story steel building.

Design was conducted using the computer program ETABS, developed by Computers and Structures Inc., USA. Three-dimensional models were used for analysis/design as well as progressive collapse investigations to avoid overly conservative structural response. It should be noted that ignoring threedimensional effects is not conservative when beams frame into exterior frames as they may induce considerable torsional effects, especially in corner columns as demonstrated by Mohamed [2]. Therefore, all interior moment frames along grid lines $\mathrm{A}$ to $\mathrm{H}$ were assumed to frame into perimeter frames along grid lines 1 and 6 using shear connections. This will theoretically eliminate torsional moments on perimeter frames.

\section{Distributed plasticity}

Mohamed and Tarmoum [5] applied the AP method to assess the potential for progressive collapse of the case study described in this paper. When column D2 was notionally removed, the maximum vertical deformation under this columns was $1342.60 \mathrm{~mm}$, when using 
nonlinear static analysis using the load combinations in Eq. 1 and Eq. 2. All of the designed w-shaped sections in Fig. 2 and Fig. 3 meet the requirements of section I2.2 of the AISC specifications [10] for prevention of local buckling. The requirements of section I2.3 [10] to control lateral torsional buckling are satisfied through the concrete-filled composite deck on top of the w-shaped beams. In order to understand the effect of distributed plasticity on the deformation response under notionally removed column, additional concentrated hinges are applied along vertical and horizontal frame elements. The results are summarized in the following subsections.

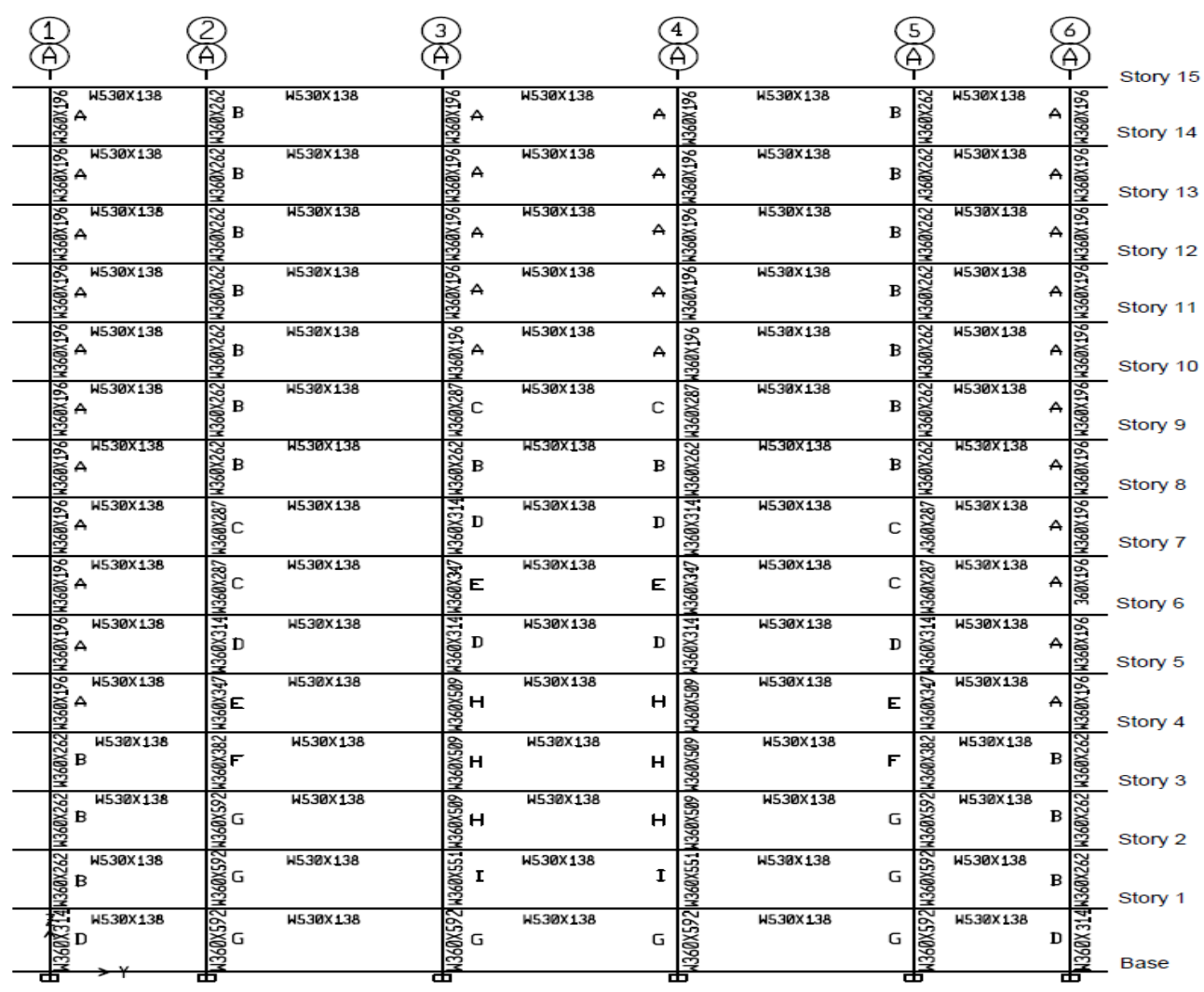

Figure 3. Elevation along grid line A, beams sections are all W530X138, column sections are; A: W360X196, B: W360X262, C: W360X287, D: W360X314, E: W360X347, F: W360X382, G: W360X592, H: W360X509, I: W360X551.

Analysis Results for Notional Removal of Interior Column D2 - Three plastic hinges assigned at the begining and at the end of each horizontal and vertical element

Mindful of the computational cost, only three plastic hinges are used at the end of each frame element to capture the effect of distributed plasticity on deformation response. When column D2 is notionally removed, the unsupported span after removal of column D2 reaches 20 meters. Analysis of the structural system with column D2 removed produced the deformed shape shown in Fig. 4 and the maximum vertical deformation response reaches $1934.6 \mathrm{~mm}$. It is noted that yielding was limited to part of the floor adjacent to the notionally removed column D2 and didn't spread to other areas of floor.

Load Increase Factor for Interior Column D2 Five plastic hinges assigned at the begining and at the end of each horizontal and vertical element

Mindful of the computational cost, number of plastic hinges is increased to three that are applied at the end of each frame element to capture the effect of distributed plasticity on deformation response. Analysis of the structural system with column D2 removed produced the deformed shape shown in Figure 5 and the maximum vertical deformation response reaches $955 \mathrm{~mm}$. Analysis of the structural system with column D2 removed produced the deformed shape shown in Fig. 5. Similar to the case of 3-plastic hinges, yielding remained within the beams surrounding the notionally removed column, and damage is essential restricted to the floor area surrounding the notionally removed column. Fig. 5 shows additional plastic hinges yielding on all beams D1-D2 at each story level, compared to the case of fewer modelled plastic hinges shown in Fig. 4. Furthermore, additional hinges formed on beams D2-D3 at the upper four stories when 5-hinges are modelled as shown in Fig. 5, compared to Fig. 4.

Figure 6 shows the members assessed for stress level based on DCR, for the model where five plastic hinges were used on each frame element. Only the two members connected to the notionally removed column failed in each floor along grid line D, namely, beams D1-D2 and D2-D3. This is because beam D1-D2 and D2-D3 became one 20-meter long beam.

\section{Summary}

The use of moment frames along the perimeter and interior of steel framed structure enhances the resistance 
to progressive collapse through limiting the response to the floor areas near the notionally removed columns. Moment resisting connections are more expensive to build compared to simple connections that are typically used with gravity systems. When notionally removed internal column is within properly design moment frame, ductile behavior may be expected during progressive collapse AP analysis, even with relatively long beams spans, similar to the ones examined in this study.

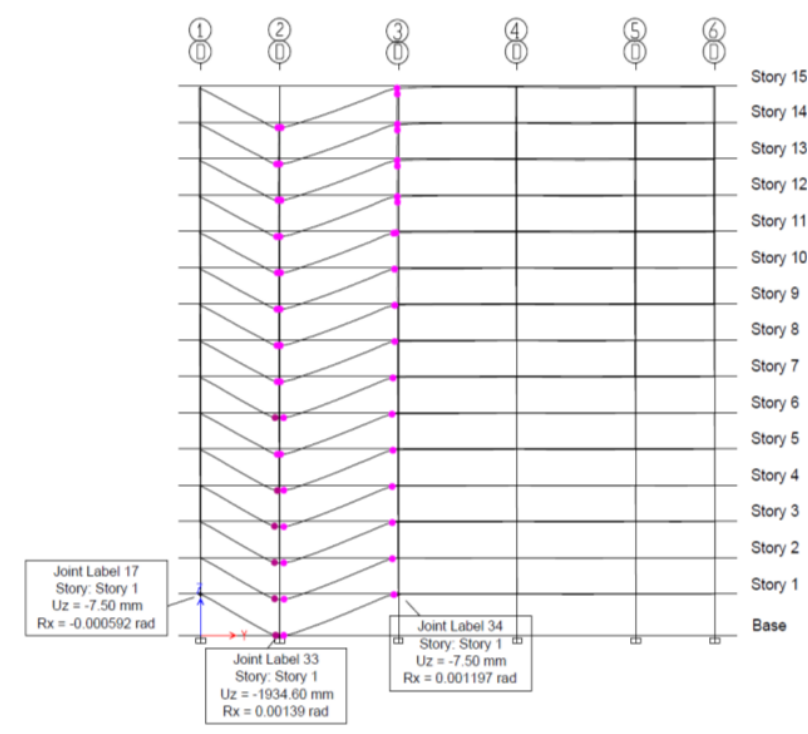

Figure 4. Deformed shape with notionally removed column D2 and parallel interior moment frames-NSP.

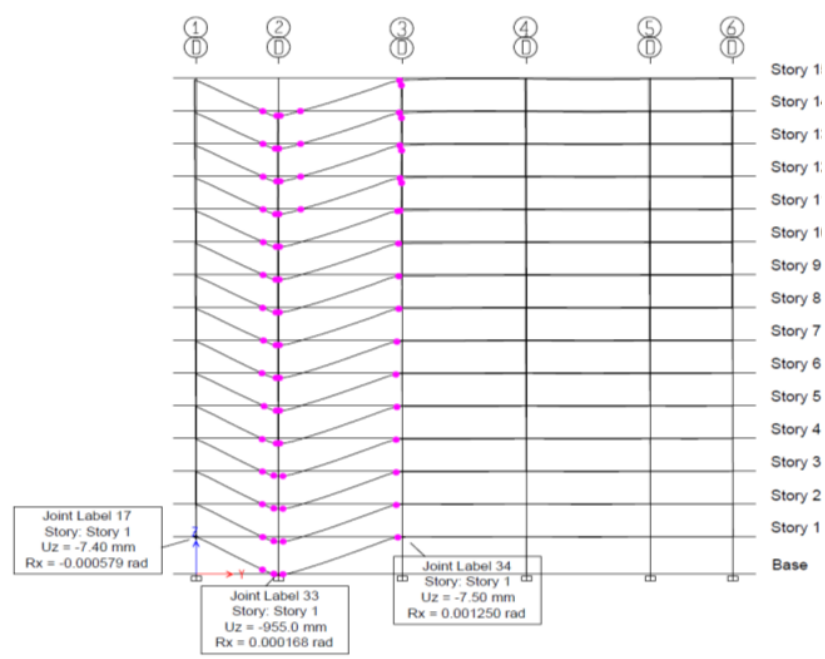

Figure 5. Deformed shape with and plastic hinges when D2 is notionally removed - each frame element modelled with five distributed hinges along.

Considering distributed plasticity using an acceptable method improves accuracy of responses obtained from AP progressive collapse analysis. It is conservative to ignore distributed plasticity in computing deformation responses. A simple approach to account for distributed plasticity that involves modelling several concentrated hinges at suitable locations may offer sufficient accuracy to predict the desired deformation-controlled behaviour. Computationally expensive models for distributed plasticity are not always necessary, particularly when considering the high level of uncertainty involved in progressive collapse assessment methods.

The findings of this study are applicable to steel structures where the lateral force resisting system consist of moment frames only, without bracing system.

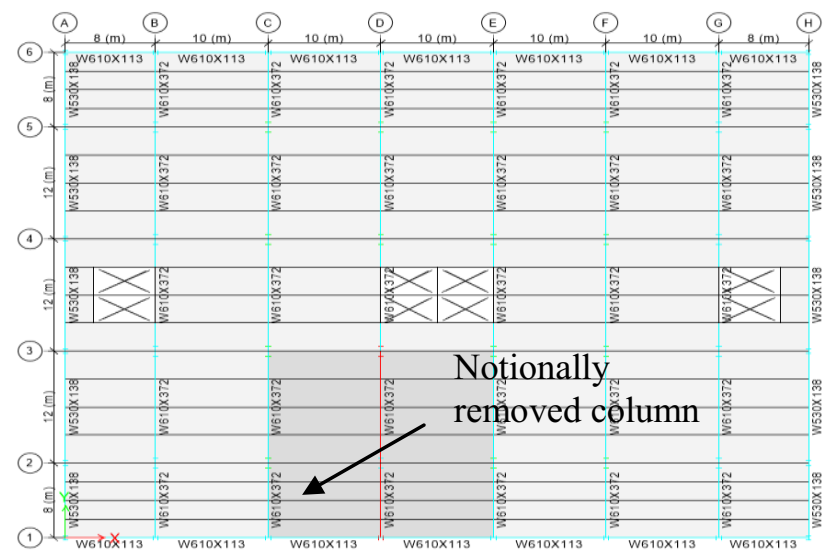

Figure 6. Beams D1-D2 and D2-D3 exceeded DCR of 1.0 due to notional column removal when each frame element is modelled with five distributed plastic hinges.

\section{Acknowledgement}

The authors gratefully acknowledge the financial support of the Center on Sustainable Built Environment and the Office of Research and Sponsored Programs at $\mathrm{Abu}$ Dhabi University.

\section{References}

1. U.S. Department of Defense, Design of buildings to resist progressive collapse, UFC 4-023-3, Unified Facilities Criteria, U.S. Department of Defense, 2013.

2. O. A. Mohamed, Assessment of Progressive Collapse Potential in Corner Panels of Reinforced Concrete Buildings, Journal of Engineering Structures, 31, 3 749-757 (2009)

3. T. Kim and J. Kim, Collapse Analysis of Steel Moment Frames with Various Seismic Connections, Journal of Constructional Steel Research, 65, 13161322 (2009)

4. K. Khandelwal, S. El-Tawil, F. Sadek, Progressive Collapse Analysis of Seismically Designed Steel Braced Frames, Journal of Constructional Steel Research, 65, 3 699-708 (2009)

5. O.A. Mohamed, M.G. Tarmoom, Alternate Path Method for Progressive Collapse Resistant Design of Steel Framed Structures, in J. Kruis, Y. Tsompanakis, B.H.V. Topping, (Editors), Proceedings of the Fifteenth International Conference on Civil, Structural and Environmental Engineering Computing, Civil-Comp Press, Stirlingshire, UK, (2015)

6. U.S. Department of Defense, Structural Engineering - UFC 3-301-01, Unified Facilities Criteria, U.S. Department of Defense, (2014). 
7. American Society of Civil Engineers, Minimum Design Loads for Buildings and other Structures ASCE/SEI 7-10, ASCE, (2010)

8. O. A. Mohamed, Calculation of load increase factors for assessment of progressive collapse potential in framed steel structures, Case Studies in Structural Engineering, 3 11-18 (2015)

9. American Society for Civil Engineers, Seismic Rehabilitation of Existing Buildings ASCE/SEI 41 6, ASCE, (2007).
10. Y. Alashker, S. El-Tawil, and F. Sadek, Progressive Collapse Resistance of Steel-Concrete Composite Floors, Journal of Structural Engineering - ASCE. 136, 10 (2010).

11. American Institute of Steel Construction, Steel Construction Manual - AISC 325 - $11-14^{\text {th }}$ Edition, $3^{\text {rd }}$ printing, AISC (2011) 